\title{
A teoria da dependência e o papel das organizações econômicas educacionais:
}

\section{reflexos nos ambientes educacionais}

\author{
Dependency theory and the role of educational economic organizations: reflexes in educational \\ environments
}

\section{La teoría de la dependencia y el papel de las organizaciones económicas educativas: reflejos en los entornos educativos}

Recebido: 26/01/2021 | Revisado: 01/02/2021 | Aceito: 02/02/2021 | Publicado: 08/02/2021

Fábio Lopes
ORCID: https://orcid.org/0000-0002-8277-0919
Petróleo Brasileiro S.A, Brasil
E-mail: mtclopes@gmail.com
Walquiria Guedert Mendes
ORCID: https://orcid.org/0000-0003-1970-1379
Eecretaria de Estado da Educação de Santa Catarina, Brasil
E-mail: walquiria.guedert@ gmail.com
Fernanda Corrêa Garcia
ORCID: https://orcid.org/0000-0002-1480-9682
E-mail: fernanda.garcia@ifsc.edu.br

\begin{abstract}
Resumo
O ensaio teórico tem como objetivo apresentar o papel da Teoria da Dependência e seus reflexos no processo de construção sociocultural brasileira. Reflete, também, sobre o papel das organizações econômicas educacionais e sua influência na política educacional brasileira, bem como as ações dos reformadores empresariais e a standartização do ensino. Do ponto de vista metodológico, este ensaio foi constituído a partir de uma abordagem qualitativa, produzido por meio de pesquisa bibliográfica e análise documental. Para dar materialidade à este ensaio teórico privilegiou-se, nas leituras, os seguintes autores: Araújo e Frigotto (2015), Moura, Leite e Ribeiro (2015), Neves e Pronko (2008), Oriques (1995) entre outros. Considera-se que, no momento atual da política educacional brasileira, temos as organizações econômicas educacionais que escondem os seus reais propósitos de criação. Difundem ideais de promoção de uma educação para todos, ofertada de forma linear, estratificada, estaticamente criada, formulada para atender públicos específicos. A preocupação latente de grandes bancos mundiais em se inserir no mercado educacional é visualizado com bastante preocupação por partes das instituições de ensino e seu quadro docente. O financiamento atrelado ao atendimento de quesitos, de metas a serem alcançadas, revelam uma tendência de base eminentemente ideológica: a servidão para o mercado.
\end{abstract}

Palavras-chave: Reforma educacional; Standartização do ensino; Policy makers; Think tanks.

\begin{abstract}
The theoretical essay aims to present the role of Dependency Theory and its reflexes in the process of Brazilian sociocultural construction. It also reflects on the role of educational economic organizations and their influence on Brazilian educational policy, as well as the actions of business reformers and the standardization of education. From a methodological point of view, this essay was constituted from a qualitative approach, produced through bibliographic research and documentary analysis. In order to give materiality to this theoretical essay, the following authors were privileged in the readings: Araújo and Frigotto (2015), Moura, Leite and Ribeiro (2015), Neves and Pronko (2008), Oriques (1995) among others. It is considered that, in the current moment of Brazilian educational policy, we have educational economic organizations that hide their real purposes of creation. They spread ideals to promote education for all, offered in a linear, stratified, statically created way, designed to serve specific audiences. The latent concern of major world banks to enter the educational market is viewed with great concern by parts of educational institutions and their teaching staff. The financing linked to the fulfillment of requirements, of goals to be achieved, reveal a trend of eminently ideological basis: servitude to the market.
\end{abstract}

Keywords: Educational reform; Standardization of teaching; Policy makers; Think tanks. 


\begin{abstract}
Resumen
El ensayo teórico tiene como objetivo presentar el papel de la Teoría de la Dependencia y sus reflejos en el proceso de construcción sociocultural brasileña. También reflexiona sobre el papel de las organizaciones económicas educativas y su influencia en la política educativa brasileña, así como las acciones de los reformadores empresariales y la estandarización de la educación. Desde el punto de vista metodológico, este ensayo se constituyó desde un enfoque cualitativo, producido a través de la investigación bibliográfica y el análisis documental. Para dar materialidad a este ensayo teórico, se privilegiaron en las lecturas los siguientes autores: Araújo y Frigotto (2015), Moura, Leite y Ribeiro (2015), Neves y Pronko (2008), Oriques (1995) entre otros. Se considera que, en el momento actual de la política educativa brasileña, tenemos organizaciones económicas educativas que esconden sus verdaderos propósitos de creación. Difunden ideales para promover la educación para todos, ofrecida de forma lineal, estratificada, creada estáticamente, diseñada para servir a públicos específicos. La preocupación latente de los principales bancos mundiales por ingresar al mercado educativo es vista con gran preocupación por parte de las instituciones educativas y su personal docente. La financiación vinculada al cumplimiento de requisitos, de metas a alcanzar, revela una tendencia de base eminentemente ideológica: la servidumbre al mercado.
\end{abstract}

Palabras clave: Reforma educativa; Estandarización de la enseñanza; Responsables políticos; Think tanks.

\title{
1. Introdução
}

O contexto educacional global sofre influências de forças que operam com fortes expectativas econômicas. O papel dos influenciadores de opinião pública (Think Tanks $^{l}$ ) e dos produtores de políticas (Policy Makers ${ }^{2}$ ) tem, cada vez mais, demonstrado seu poder de influência nos países posicionados na periferia do sistema capitalista. Situados em um contexto de padronização de ensino, a standartização do processo educacional nos países periféricos se dá pelo trabalho de agências que incorporam conceitos oriundos do processo produtivo, aplicando-os no ambiente escolar.

Cada vez mais, os atores da comunidade escolar vão perdendo espaços para estes novos personagens, que transmitem uma inovação pedagógica que atua em prol do interesse de determinados grupos hegemônicos, com fortes vertentes de natureza capitalista. A prática docente se vê sob forte influência de novas forças em ação, que propagam e difundem um ensino pré-programado, apostilado e pré-formatado: o ambiente escolar perde o caráter de artesania, para se tornar uma linha de produção com uma nova vestimenta do Toyotismo e do Neotaylorismo.

Sob esta perspectiva, o ensaio teórico, aqui apresentado, tem como objetivo apresentar o papel da Teoria da Dependência e seus reflexos no processo de construção sociocultural brasileiro. Reflete, também, sobre o papel das organizações econômicas educacionais e suas influências na política educacional brasileira, bem como as ações dos reformadores empresariais e a standartização do ensino, principalmente nos países periféricos. Na sequências, apresenta-se os procedimentos metodológicos utilizados para a realização da pesquisa aqui apresentada.

Para atingir o objetivo apresentado anteriormente, o texto, na sequência, está estruturado em 5 momentos assim nomeados: (a) procedimentos metodológicos; (b) fundamentação teórica - (b.1) a teoria da dependência moderna e seus reflexos no processo socioeducativo brasileiro; (b.2) o papel das redes sociais e sua influência na política educacional; (b.3) uma grande teia social: os reformadores empresariais e as redes sociais e, (b.4) a standartização do ensino nos países periféricos.

Por fim, destacam-se as considerações finais e as referências teóricos privilegiados nesta discussão.

\footnotetext{
${ }^{1}$ Instituições de formação de opinião pública de iniciativas de mobilização e ações coordenadas possibilitam a investigação e interpretação de que estas organizações tem o potencial de atuarem como movimentos sociais regressivos, na defesa de agenda política com elementos liberais e conservadores. (Barbosa, 2016), (Hauck, 2017), (Mendes; Peroni, 2020), (Carlotto, 2018).

${ }^{2}$ Pode-se definir um Policy Maker como um formulação de ideias ou planos que são usados por uma organização ou governo como base para a tomada de decisões. Nesta perspectiva as dimensões sociais, culturais, institucionais e históricas que estão no cerne dos sistemas nacionais de ensino [...] são cuidadosamente ignoradas e ocultadas sob afirmações de enaltecimento respeitoso da diversidade e das diferenças. Aquelas são questões remetidas para o foro nacional, enquanto as metas designadas para convergência supranacional aparecem tratadas como questões técnicas, politicamente neutras e consensualmente estimáveis sob o desígnio da eficiência e da eficácia necessárias para responder aos desafios do futuro. (Antunes, 2005, p. 133). Também importante destacar estudo de Souza e Barbosa (2011), Rosseto; Gonçalves (2015), Aprile; Barone (2009) e Almeida (2014).
} 


\section{Procedimentos Metodológicos}

Do ponto de vista metodológico, este ensaio foi constituído a partir de uma abordagem qualitativa e dialética, produzido por meio de pesquisa bibliográfica e análise documental. Para dar materialidade à este ensaio teórico privilegiou-se, nas leituras, os seguintes autores: Araújo e Frigotto (2015), Moura, Leite e Ribeiro (2015), Neves e Pronko (2008), Oriques (1995) entre outros.

Para Pereira; Shitsuka; Parreira e Shitsuka (2018),

1) A pesquisa qualitativa, em geral, ocorre no ambiente natural com coleta direta de dados e o pesquisador é o principal instrumento; 2) Os dados coletados são preferencialmente descritivos; 3) A preocupação do processo é predominante em relação à do produto; 4) O "significado" que as pessoas dão as coisas e a sua vida são focos de atenção para o pesquisador e, 5) A análise de dados e informações tende a seguir um processo indutivo. (Pereira; Shitsuka; Parreira \& Shitsuka, 2018, p. 67),

Para Silva e Pasqualli (2020, p. 4), “a metodologia de um estudo puramente teórico não pode fugir de um caminho que é exclusivo, isto é, o da pesquisa bibliográfica”. Esta pesquisa é desenvolvida com base em material já elaborado, constituído principalmente de livros e artigos científicos. Os dados oriundos da análise documental vale-se de materiais que não receberam ainda um tratamento analítico, ou que ainda podem ser reelaborados de acordo com os objetos da pesquisa. Além de analisar os documentos de "primeira mão" (documentos de arquivos, igrejas, sindicatos, instituições etc.), existem também aqueles que já foram processados, mas podem receber outras interpretações, como relatórios de empresas, tabelas etc. (Gil, 2008).

Na sequência, apresenta-se a fundamentação teórica que deu materialidade à este texto.

\section{Fundamentação Teórica}

\subsection{A teoria da dependência moderna e seus reflexos no processo socioeducativo brasileiro}

A Teoria da Dependência3 nunca se fez tão presente no contexto nacional quanto nos últimos anos já que o Brasil, historicamente, tornou-se um país que importa tecnologia e exporta produtos essenciais para o resto do mundo cabendo-nos, apenas, o papel de mero exportador de produtos agrários (fontes de matérias primas).

Neste contexto, alimentamos o mundo e não conseguimos educar com dignidade as novas gerações brasileiras já que não agregamos tecnologias em nossos meios de produção. Se a tecnologia e seu aprendizado não são assimilados, a educação falha e o próprio conceito de nação também.

Destarte, o aprendizado de todo o processo produtivo nacional deverá passar por sólidas bases de conhecimento técnico e tecnológico, mas somente isto não bastará para nos afastarmos da condição de país posto às margens dos países desenvolvidos já que é preciso quebrar os grilhões da dependência dos países acima da linha do Equador.

Vislumbra-se, assim, uma formação voltada não para o capital, mas que permita ao estudante e ao trabalhador um sentido de existência próprio, uma educação de caráter omnilateral, libertadora e que consiga conciliar as exigências do sistema produtivo com a satisfação pessoal deste ser humano.

Nesta direção, compreende-se que uma educação omnilateral não se faz da noite para o dia já que necessita-se de investimentos profundos em uma matriz curricular que ofereça aos estudantes uma formação voltada para o 'pensar' quais os

\footnotetext{
${ }^{3}$ A teoria da dependência é uma formulação teórica desenvolvida por intelectuais como Ruy Mauro Marini André Gunder Frank, Theotonio dos Santos se outros e consiste em uma leitura crítica e marxista não-dogmática dos processos de reprodução do subdesenvolvimento na periferia do capitalismo mundial, em contraposição às posições marxistas convencionais dos partidos comunistas e à visão estabelecida pela Comissão Econômica para a América Latina e o Caribe.(Oriques, 1995), (Machado, 1999), (Martins; Filgueiras, 2018).
} 
impactos do seu trabalho para a sociedade, ao 'reconhecer' o sentido ontológico do seu trabalho, à 'compreender' como seu trabalho pode ser melhorado entre outros grandes e importantes questionamentos.

Estas percepções, necessária aos estudantes, não se moldam nos conceitos e ideologias propagadas pelas teorias neoliberais como no currículo por competências e na teoria do capital humano que somente formam o estudante para o mercado de trabalho, não os formando para a vida. Na formação por meio destas perspectivas teóricas, qualquer alteração que ocorra no processo produtivo local, repercutirá em vários critérios da vida deste estudante/trabalhador (empregabilidade, nível de consumo, qualidade de vida, expectativa de vida, saúde metal, entre outros), pois o mesmo não teve uma formação voltada para a vida e sim para o capital.

Neste viés, a formação omnilateral tem apresentado características de ser uma educação de índole libertadora, pois permite que o estudante reflita sobre onde está inserido no meio de produção e qual o seu papel na vida, seu sentido de existência. Nesta formação, o conceito de interdisciplinaridade é posto: o estudante é orientado a cursar componentes curriculares que lhe projetem novos horizontes, como a Filosofia, a Sociologia e a História.

Refletir sobre o mundo e seus contextos ficou relegado as classes mais abastadas ao longo de toda nossa história. Para a classe subalterna, não é dada a oportunidade de pensar sua existência e seu papel no contexto social de sua época. Para tanto, as classes proprietárias dos meios de produção, enviavam seus filhos para uma formação clássica nas universidades Europeias, enquanto o restante da sociedade engajava-se na execução dos processos de produção.

Nesta esteira, o Brasil teve um papel fundamental no contexto mundial: durante o seu processo de formação enquanto nação, teve-se um dos maiores processos escravistas da história da humanidade. Toda a massa de escravos era direcionada para a execução de tarefas de natureza braçal e toda a técnica empregada para a execução destas tarefas, era ditada pelo homem branco, dito superior e culto.

Assim, enquanto a fazenda era tocada pelo fazendeiro e sua leva de escravos e encarregados, seus filhos usufruíam da melhor educação existente na época: aprendiam Artes, Filosofia, Ciência Política entre tantas outros componentes curriculares. Este processo histórico teve consequências nefastas no campo educacional brasileiro, perpassando várias gerações até os nossos dias. Nesta linha, Moura e Frigotto (2015) destacam que:

A formação é produto das relações sociais e de produção, e a escola, espaço institucionalizado onde também existe parte dela, é fruto de tais relações. Dessa forma, não foi essencial, inicialmente, mas um luxo, porque foi concebida para atender aos interesses de uma determinada classe, a dos dirigentes. (Moura; Frigotto, 2015, p.1059).

Historicamente, durante vários séculos, grande parte da população brasileira não obteve do Estado o merecido investimento em educação básica, média e superior. Este ciclo vicioso criou uma massa populacional desprovida de esperança e no pensar em seu existir. Para este trabalhador, trabalha-se por trabalhar, trabalha-se para poder comer e viver, perdendo, então, o sonho e o encanto pela vida.

Mostra-se assim, que o nosso caráter de dependência, não está somente vinculado ao campo econômico e comercial. Nosso processo histórico revela vários ciclos e subciclos de dependência menores, em diferentes setores da sociedade, como no campo educacional. Criam-se modelos educacionais direcionados para o capital e para o mercado, não levando em conta nossa dívida histórica com determinados setores populacionais.

Quebrar este processo de dependência econômica e educacional requer um esforço coletivo, em que participem todos os segmentos da sociedade, principalmente aqueles que foram prejudicados no processo histórico de formação enquanto nação brasileira.

Uma das propostas elencadas está direcionada a educação de nível médio integrada a educação profissional. Acerca disto, Frigotto (2015), afirma que o ensino médio integrado se compromete com uma formação inteira e de natureza utópica. 
Fundir o mundo do trabalho com uma sólida formação humana, parece-nos ser um caminho para uma prática educacional de caráter genuinamente inclusivo, tendo como referência o homem e não o mercado.

Neste caminho temos as palavras de Moura e Frigotto (2015), que nos fornece a pista de que o ensino deve se fundamentar nos conceitos de integração e politecnia, tal qual propostos nos estudos de Marx:

Partiremos do pressuposto de que tanto na formação onilateral, politécnica ou integral, cuja gênese está na obra de Marx e Engels, como na escola unitária, de Gramsci, não há espaço para a profissionalização stricto sensu quando se trata da formação de adolescentes, tendo como referência a emancipação humana. Segundo esses autores, formar, ainda na adolescência, o sujeito para uma determinada profissão potencializa a unilateralidade em detrimento da onilateralidade. (Moura; Frigotto, 2015, p.1065).

A educação de caráter integrado, politécnico e onilateral vai ao encontro da inclusão e transformação na vida das pessoas, unindo categorias essenciais do mundo do trabalho, da educação e do ensino. Entrementes, ao longo dos anos, esta vertente educacional vem sofrendo repetidos ataques em função da supremacia de alguns interesses hegemônicos ligados ao mercado.

\subsection{O papel das organizações econômicas e sua influência na política educacional}

Contrariando os projetos políticos ideológicos centrados no ser humano, as propostas de ensino de caráter neoliberal se espalham no mundo e na terra brasilis, tendo como centro difusor os países do Hemisfério Norte e organizações notadamente do mercado financeiro como o Banco Internacional de Desenvolvimento (BID) e o Fundo Monetário Internacional (FMI) e, de caráter institucional, como a Organização para a Cooperação e Desenvolvimento Econômico (OCDE) e a Organização Internacional do Trabalho (OIT).

Tais redes propõem uma reforma educacional baseada nos interesses do mercado financeiro, inspiradas em escolas que adotam o padrão Bolonha e Turim. Existe uma agenda globalmente estruturada, com fortes expectativas econômicas no mercado da educação em países subdesenvolvidos e em desenvolvimento.

Busca-se influenciar e pressionar a política educacional de países como o Brasil, por meio do controle e da difusão de informações que propiciam o afastamento do Estado das questões educacionais, direcionando este filão de mercado para as instituições mercadológicas: as instituições privadas, que lucram com a ausência da figura do Estado.

O potencial destes mercados pode ser analisado sob a ótica dos influenciadores de opinião pública (Think Tanks) e dos produtores de políticas (Policy Makers). Adota-se uma postura de conquista de mercado - muitas vezes a ideologia do vencedor se alastra por meio de quantificação dos números escolares.

Programas vinculados a outras disciplinas, avaliam numericamente tudo que é produzido pela educação, quantifica-se tudo: número de estudantes, consumo de insumos, caráter ideológico dos professores, gastos com reformas, número de egresso. Todo o percurso formativo do estudante é numericamente estratificado, alimentando um banco de dados das instituições que se beneficiam deles, moldando-os ao seu bel prazer, servindo-se dos mesmos dados para a promoção de políticas hegemônicas de determinados grupos, grupos de interesse vinculados ao caráter escravista do capital.

Neste ideário propagado por determinados grupos mercantis, difundido em todos os estratos da população, a educação é estudada sob o ponto de vista empresarial; sob os fundamentos de conceitos vinculados a eficácia e do rendimento.

A educação por si só torna-se um negócio, um comércio: novas definições de gestão escolar e empreendedorismo são propaladas abertamente; o espaço do saber é sobrepujado por um currículo que direciona o corpo discente para o vetor da competência mercantil. 
Nesta concepção de mercantilização, as universidades públicas também tornam-se alvos da agressividade da exploração monetária - novamente temos a velha regra de quantificar tudo, de maneira estatisticamente perfeita, em prol de interesses escusos.

Muitos municípios, principalmente os localizados no interior, afastados dos grandes centros urbanos, contratam tais Instituições de Ensino para lhes prestar assessoria técnica em matéria de educação, relegando ou até mesmo menosprezando, grandes centros de ensino de Universidades Públicas, que tem que tem sua história voltada para a pesquisa em educação.

Assim, grandes organizações econômicas educacionais de influência podem ser citados: Rede Atlas, Fundação Airton Senna, o Programa Todos pela Educação, a Fundação Pensar (Argentina), Grupo Millenium e Fiesp são alguns exemplos. A dispersão do ideário do mercado se dá por diferentes formas, assunto que analisaremos no próximo capítulo.

\subsection{Uma grande teia social: os reformadores empresariais e as organizações econômicas educacionais}

Se pudermos abstrair determinados conceitos oriundos do papel que as organizações econômicas educacionais promovem, veremos que a mesma é vista sob a ótica de uma grande teia de aranha. Nos pontos de interconexão, poderemos ver as instituições que propagam as informações advindas das agências que servem os interesses do capital mercadológico.

Destaca-se a forma como as notícias são atomizadas, que são basicamente através de: a) Textos escritos, b) Internet, c) Seres humanos e d) Poder do capital (dinheiro), entre outros. Assim, esta grande teia se espalha na sociedade, sempre utilizando-se dos conceitos educacionais advindos de países estrangeiros.

Nesta vertente, a dita e tão propagada Escola de Chicago, aparece como um dos principais polos de irradiação ideológica. Não basta só atacar e monetarizar a educação, é necessário promover uma agenda ampla que discuta privatizações de empresas e órgãos públicos; a reforma da previdência, a privatização de setores como a saúde, redes de atendimento de distribuição de água e saneamento básico, entre outros.

Por demais, ainda neste viés, divulgam-se a necessidade de aumentar o número de concessões para a iniciativa privada, diminuindo o tamanho do Estado, enxugando-o em prol de uma política que serve os interesses específicos de determinados grupos.

A conjectura acima exposta, nos fornece um panorama em que as entidades de defesa de classe dos docentes vão sendo gradativamente fragilizadas. No contexto empresarial de educação, o papel do professor é secundário, pois o mesmo é visto como um propagador de ideologias contrários ao sistema capitalista.

Busca-se a figura do tutor, alguém preparado para aplicar uma determinada receita escolar, para um grupo específico, seguindo rigorosos critérios de experimentação social, tudo em busca da máxima eficiência do processo; a sala de aula torna-se um laboratório.

Assim, a identidade escolar em nível microrregional, vai perdendo paulatinamente sua identidade enquanto comunidade, visto que pacotes educacionais vendidos pelas corporações internacionais vão tomando espaços sociais de forma ampla e irrestrita.

\subsection{A standartização do ensino nos países periféricos: o caso do México}

O campo do processo produtivo industrial empresta, cada vez mais, conceitos a serem utilizados por novas teorias educacionais voltadas para o mercado. Um destes conceitos volta-se para a padronização daquilo do que é ensinado nas salas de aula - a standartização de conhecimentos é um dos principais meios para a uniformização do que é ensinado.

Assim, como a matriz de produção sofre transmutações ao longo do tempo (a migração do modelo Taylorista para o Toyotismo, por exemplo), a inovação pedagógica também sofre influências do mercado. Este dita as regras do que se deve ser ensinado, de maneira padronizada, em sala de aula. 
Um carro sai da linha de produção de forma uniforme, igual, padronizado. Neste modelo educacional, oriundo do mercado, os estudantes podem ser comparados a linha de produção de uma montadora de veículos: Todos os estudantes devem aprender aquilo que é posto pelo mercado, perdendo-se identidades sociais que foram construídas ao longo da História.

Se analisarmos este panorama educacional sob a ótica de determinados grupos minoritários (Quilombolas, Deficientes Físicos, Comunidades Indígenas e Mulheres em situação de vulnerabilidade social) teremos um problema de grau gigantesco, pois cada grupo social apresenta características de formação e de convívio próprias, num determinado contexto social específico.

Países periféricos do sistema capitalista global tornaram-se excelentes laboratórios de experimentação das ditas políticas de standartização do ensino (México, Brasil, Argentina e Chile são alguns exemplos). Neste contexto temos as palavras Neves e Pronko (2008):

\begin{abstract}
De modo geral, a trajetória das políticas educacionais dos organismos internacionais para a América Latina e Caribe segue a mesma trajetória histórica das diretrizes políticas em nível mundial, em especial aquelas destinadas aos países em desenvolvimento. Suas intervenções na área educacional se iniciam também na região nos anos 1960, voltadas primeiramente para a formação técnico-profissional e, mais tarde, para a expansão da educação elementar. Até os anos iniciais de 1980, elas se dirigem para o desenvolvimento de programas e projetos de educação e de saúde, com vistas a aumentar a produtividade do trabalho e a formar atitudes favoráveis ao bloco capitalista nos tempos de Guerra Fria, embora, de forma incipiente, também tenham se direcionado ao fomento à expansão da educação superior, com a finalidade de formar os intelectuais orgânicos do processo de modernização capitalista regional, sob a ideologia do desenvolvimentismo e do americanismo. (Neves; Pronko, 2008, p. 100).
\end{abstract}

O México, foi escolhido para ser um dos percursores da standartização de ensino, por situar-se em uma região de transitoriedade geográfica (primeiro mundo e terceiro mundo, países desenvolvidos e países em desenvolvimento). As grandes corporações internacionais implantaram um sistema que utilizou os Think Tanks e os Policy Makers para influenciar a opinião pública Mexicana, em defesa de um projeto que beneficiaria a padronização de ensino na rede educacional Mexicana.

No cenário Mexicano, uma quantidade enorme de atores externos do universo escolar, atuaram na implantação do novo sistema; a rotatividade de docentes elevou-se de maneira espantosa e implantou-se a Pedagogia dos Objetivos e do Neoconstrutivismo. Houve uma campanha midiática espantosa em prol dos interesses das grandes Corporações.

As antigas técnicas empregadas nas grandes indústrias foram remodeladas para uma nova inserção dentro do ambiente escolar: o Neotaylorismo surge com força, com a Taylorização do trabalho docente, com o controle de tempos em todas as etapas de aprendizagem.

\title{
4. Considerações Finais
}

A nova gestão pública nascida na Inglaterra, que incutiu a ideia da formulação de um novo Estado gerencial, que entrega suas funções básicas para a iniciativa privada foi a tônica escolhida pelos grupos mercantis para a exploração de ramos como a educação, a saúde e a previdência privada. O Estado de bem-estar social se apequena, frente a cobiça de corporações que querem exaurir e explorar, sempre mais, as garantias que deveriam ser fornecidas às toda população.

A arrecadação Federal promoverá o enriquecimento dos banqueiros, titulares absolutos da dívida pública arcada pela Federação. Não se pagará a dívida em si, antes disso, se quitará os juros da dívida pública, em uma espécie de moto-perpetum. Nesta visão, a justiça social não poderá desenvolver todas as suas potencialidades de distribuição de renda.

Se a base da pirâmide social não encontra motivos para se ter esperança, com a falta de educação e da saúde, nascerão autênticos bolsões de miséria, que pressionarão, em algum momento histórico, as classes mais abastadas. A distribuição de 
renda e o padrão mínimo de consumo para a população, são as garantias que deverão ser preservadas para a manutenção de uma autentica paz social.

Contrariando esta visão, temos uma política de índole deliberadamente neoliberal, que confisca, retirando toda a esperança de mudança das classes menos abastadas: supre-se tudo e insere-se até o que deve ser aprendido pelos estudantes.

A nova roupagem do neoliberalismo vem carregada de termos técnicos oriundos das ciências da administração; uma linguagem pomposa, mas que carrega uma carga de significado e significantes muito clara: atender ao mercado do capital.

Se olharmos sob o viés educacional, analisaremos vertentes que trabalham com o currículo por competência, a teoria do capital humano ou formas ideológicas com variantes serviçais do mercado, como a escola nova. Neste contexto, temos uma base trabalhadora que funciona como uma espécie de reserva de mão de obra para o mercado de trabalho - que se qualifica, mas que não encontra seu espaço dentro do sistema.

Destaca-se, que se o padrão mínimo de consumo não é alcançando, surgem problemas de índole social dos mais diversos tipos: aumento de violência, desagregação social, aumento do número de desempregados e a desesperança em um futuro melhor.

Formas de difusão ideológica sempre existiram em vários períodos da história da humanidade; imprensa, jornais, revistas, clubes, associações entre outras. De certo modo, o caráter de pessoalidade existia, trabalhava-se com variáveis concretas e palpáveis.

No momento atual da política educacional brasileira, temos as organizações institucionais que escondem o seus reais propósitos de criação. Difundem ideais de promoção de uma educação para todos, ofertada de forma linear, estratificada, estaticamente criada, formulada para atender públicos específicos.

A preocupação latente de grandes bancos mundiais em se inserir no mercado educacional é visualizado com bastante preocupação por partes das instituições de ensino e seu quadro docente. O financiamento atrelado ao atendimento de quesitos, de metas a serem alcançadas, revelam uma tendência de base eminentemente ideológica: a servidão para o mercado.

Como sugestões de trabalhos futuros, acredita-se que ser importante análises no campo teórico e empírico com docentes e estudantes de organizações econômicas educacionais afim de verificar a materialização da ação docente e dos resultados do processo de aprendizagem.

\section{Referências}

Aprile, M. R., \& Barone, R. E. M. (2009), “Educação Superior: Políticas Públicas para Inclusão Social”. Revista Ambiente Educação, 2(1), 39-55. https://www.scielo.br/scielo.php?script=sci_nlinks\&pid=S0011-5258201500030079100005\&lng=en

Almeida, A. T. C de. (2014), "Determinantes dos Piores e Melhores Resultados Educacionais dos Alunos da Rede Pública de Ensino Fundamental no Brasil". Planejamento e Políticas Públicas, (42), 147-187. https://www.scielo.br/scielo.php?script=sci_nlinks\&pid=S0011-5258201500030079100001\&lng=en

Antunes, F. (2005). Globalização e europeização das políticas educativas: percursos, processos e metamorfose Globalização e europeização das políticas educativas: percursos, processos e metamorfoses. Sociologia, Problemas e Práticas, Oeiras, (47), 125-143, jan. http://www.scielo.mec.pt/scielo.php?script=sci_arttext\&pid=S0873-65292005000100007\&lng=pt\&nrm=iso.

Araújo, R. M. de L., \& Frigotto, G. (2015). Práticas pedagógicas e ensino integrado. Revista Educação em Questão, 52(38), 61-80.

Barbosa, J. R. (2016). Protestos da direita no Brasil contemporâneo: think tank, grupos empresariais, intelectuais e aparelhos orgânicos da burguesia. Lutas Sociais, 20(36), 151.

Carlotto, M. C. (2018). Inevitável e imprevisível, o fortalecimento da direita para além da dicotomia ação e estrutura: o espaço internacional como fonte de legitimação dos Think Tanks latino-americanos. PLURAL, 25(1), 63-91.

https://webcache.googleusercontent.com/search?q=cache:d3TAPIjjXekJ:https://www.revistas.usp.br/plural/article/download/149014/146177/+\&cd=9\&hl=ptBR\&ct=clnk\&gl=br\&client=ubuntu.

Gil, A. C. (2008). Como elaborar projetos de pesquisa. (4a ed.), Atlas.

Hauck, J. C. R. (2017). What are 'Think Tanks'? Revisiting the Dilemma of the Definition. Brazilian Political Science Review, 11(2), e0006.

Machado, L. T. (1999). A teoria da dependência na América Latina. Estudos Avançados, 13(35), 199-215. https://doi.org/10.1590/S010340141999000100018. 
Research, Society and Development, v. 10, n. 2, e15210212391, 2021

(CC BY 4.0) | ISSN 2525-3409 | DOI: http://dx.doi.org/10.33448/rsd-v10i2.12391

Martins, C. E., \& Filgueiras, L. (2018). A teoria marxista da dependência e os desafios do século XXI. Caderno CRH, 31(84), 445-449. https://doi.org/10.1590/s0103-49792018000300001

Mendes, V., \& Peroni, V. (2020). Estado, mercado e formas de privatização: a influência dos think tanks na política educacional brasileira. Revista Espaço Pedagógico, 27(1), 65-88. http://seer.upf.br/index.php/rep/article/view/10575.

Moura, D. H., Leite, D., \& Ribeiro, M. (2015). Politecnia e formação integrada: confrontos conceituais, projetos políticos e contradições históricas da educação brasileira. Revista brasileira de Educação, 20(63).

Neves, L. M. W., \& Pronko, M. A. (2008). O mercado do conhecimento e o conhecimento para o mercado: da formação para o trabalho complexo no Brasil contemporâneo. EPSJV.

Oriques, N. D. (1995). La teoria marxista de la dependencia: una historia crítica. Tese de Doutorado. Universidade Autônoma do México. http://tede.ufsc.br/teses/MX0022-T.pdf.

Pereira, A. S., Shitsuka, D. M., Parreira, F. J., \& Shitsuka, R.(2008). Metodologia da Pesquisa Científica. https://repositorio.ufsm.br/bitstream/handle/1/15824/Lic_Computacao_Metodologia-Pesquisa-Cientifica.pdf?sequence=1

Rossetto, C. B. de S., \& Gonçalves, F. de O. (2015). Equidade na Educação Superior no Brasil: Uma Análise Multinomial das Políticas Públicas de Acesso. Dados, 58(3), 791-824. https://dx.doi.org/10.1590/00115258201559.

Silva, V. G. da, \& Pasqualli, R. (2020). A atualidade da pedagogia socialista soviética: um ensaio teórico. Research, Society and Development, 9(7). https://rsdjournal.org/index.php/rsd/article/view/4388.

Souza, Â. R., \& Barbosa, A. G. (2011). Os trabalhadores docentes da educação básica no Brasil em uma leitura possível das políticas educacionais. Education Policy Analysis Archives/Archivos Analíticos de Politicas Educativas, 19, 1-22. https://www.redalyc.org/pdf/2750/275019735035.pdf. 